\title{
Las escuelas de la inmigración en la ciudad de Santiago: Elementos para una educación contra el racismo
}

\author{
María Emilia Tijoux ${ }^{1}$ \\ Universidad de Chile, Santiago, Chile. Email: emiliatijoux@gmail.com
}

\begin{abstract}
Resumen: Las escuelas públicas de los barrios segregados de Santiago se han ido vaciando de alumnos chilenos cuyos padres reubican en otras escuelas, pero gracias a la llegada de niñas y niños hijos de inmigrantes, consiguen seguir funcionando. Son escuelas situadas en el centro de la ciudad, en sectores que dan cuenta del abandono del Estado y de la agonía de calles adoquinadas y casonas señoriales ahora convertidas en alojamientos baratos para inmigrantes. En este escenario, los niños provenientes de la inmigración devienen actores secundarios, pero debido a las crisis son finalmente protagonistas de la sobrevida de la institución escolar. Niños útiles, que permiten la continuidad de las escuelas al mismo tiempo que son maltratados por su origen. El propósito de este artículo es dar cuenta del racismo cotidiano que viven los hijos de inmigrantes peruanos a partir del habla que despliegan los adultos de la comunidad educativa que los acoge. ¿Cómo los caracterizan, cómo los evalúan? ¿Es acaso la extranjeridad heredada de sus padres la frontera que impide su integración?
\end{abstract}

Palabras clave: inmigración peruana, hijos de inmigrantes peruanos, racismo, extranjeridad, frontera.

\section{Immigration schools in the city of Santiago: Elements for an education opposing racism}

\begin{abstract}
Public schools in segregated neighbourhoods of Santiago are being emptied of chilean students whose parents relocate in other schools, but thanks to the arrival of immigrant children, schools manage to continue operating. They are schools located downtown, in sectors that account for the abandon of the state and the agony of paved streets and noble mansions, now converted into budget accommodation for immigrants. In this scenario, children of immigration become secondary players, but because of the crisis are finally protagonists of the survival of the educational institution. Useful children that allow continuity of schools while they are mistreated by their origin. The purpose of this article is to describe everyday racism experienced by Peruvian immigrant children based on the speech that adults of the educational community that welcomes them display. How are they characterize, how are they evaluated? Is the foreignness inherited from their parents, the frontier that prevents their integration?
\end{abstract}

Key words: peruvian immigration, peruvian immigrant children, racism, foreignness, frontier. 


\section{Escolas de imigração na cidade de Santiago: elementos para uma educação contra o racismo}

Resumo: As escolas públicas dos bairros segregados de Santiago foram esvaziados de estudantes chilenos que os pais mudaram para outras escolas, mas com a chegada de crianças filhos de imigrantes, eles conseguem continuar operando. Estas escolas estão localizadas no centro da cidade, em setores que representam o abandono do estado e da agonia de ruas e mansões, agora transformada em alojamento barato para imigrantes. Neste cenário, as crianças de imigração se tornarem jogadores secundários, mas devido à crise são protagonistas em última análise, da sobrevivência da escola. Crianças útil, permitindo a continuidade das escolas, enquanto eles são maltratados por sua origem. O objetivo deste artigo é descrever o racismo cotidiano vivido por filhos de imigrantes peruanos a partir do discurso adulto da comunidade educativa implantada que os acolhe. Como caracterizar-los, como avaliá-los? É a estranheza que herdou de seus pais a fronteira que impede a sua integração?

Palavras-chave: imigração peruana, filhos de imigrantes peruanos, racismo, estranheza, fronteira.

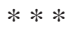

La negrería que huele a cebolla frita vuelve a encontrar en su sangre derramada el sabor amargo de la libertad. Y está de pie la negrería.

Aimé Cesaire

\section{Introducción}

El presente artículo surge de una investigación que se planteó dos objetivos principales: comprender y analizar la vida cotidiana de las niñas y los niños hijos(as) de inmigrantes peruanos en los espacios sociales de las escuelas donde cursan enseñanza básica e identificar y analizar capitales, estrategias y tácticas que despliegan en los encuentros cotidianos de sus escuelas. Este ejercicio comprensivo se llevó a cabo en cuatro escuelas de Santiago. Metodológicamente, optamos por un enfoque cualitativo que privilegió la técnica de la observación. Se utilizó la entrevista en profundidad y la técnica del recorrido comentado para acercarse a los adultos; para abordar a los niños se llevó a cabo la técnica del mapa parlante, que dio a conocer sus puntos de vista respecto a los encuentros en los espacios escolares, a los itinerarios entre la escuela y sus casas y las principales interacciones entre ellos, con otros hijos de inmigrantes, con niños chilenos y con adultos de la comunidad educativa. A partir de un trabajo etnográfico indagamos los usos y las apropiaciones de los espacios como los lazos de afectos que tejían o no con ellos y así conocimos los capitales que permitían descifrar sus vínculos con directores, inspectores, profesores y diversos trabajadores de las escuelas. Tales opciones metodológicas minimizaron la violencia simbólica contenida en entrevistas y encuentros no preparados, y permitieron conocer las interacciones y comprender las significaciones que los ni- 
ños y los adultos construían sobre sus estas escuelas.

Teóricamente, las opciones respondieron a las necesidades metodológicas señaladas. Por una parte dimos cuenta de ciertas estructuraciones del problema y por otra ingresamos en la vida cotidiana o en la vida misma como normalidad y costumbre. Para llevar a cabo este propósito, autores como Bourdieu, Goffman, Foucault, de Certeau, entre otros, fueron relevantes, del mismo modo que lo fueron los antecedentes socio-históricos, culturales y políticos respecto a la cuestión migratoria en Chile, en particular sobre la migración peruana del siglo XXI y los trabajos que aludían a los niños hijos de inmigrantes. Sobre la situación de niñas y niños provenientes de la inmigración revisamos una interesante literatura nacional e internacional debido a la similitud que presenta el problema en distintos países y enfatizamos la importancia de investigaciones nacionales realizadas por I. Pavez (2010), C. Stefoni (2003) y P. Hevia (2009), al igual que los trabajos del Colectivo Sin Fronteras (2007) y de Unicef (2010), entre otros.

La investigación duró dos años: el primero estuvo dedicado al trabajo de terreno y el segundo al análisis, considerando siempre a los hijos de inmigrantes como protagonistas en el campo de la inmigración peruana que hoy se ha convertido en un sub-campo de las migraciones en Chile. Sin embargo, el trabajo no se detuvo únicamente en el problema migratorio y buscó en la cotidianeidad de los espacios escolares distintos elementos del discurso adulto que daban cuenta de discriminación y racismo contra los niños. Debemos aclarar que ante la imposibilidad de dar cuenta de todos los resultados de este estudio, el artículo privilegia el lugar y la responsabilidad que le cabe a los adultos que conforman la comunidad educativa que acoge a los niños hijos de inmigrantes, con vistas a una inserción que permita su la integración a la institución escolar chilena.

Ha sido solo después de mucha búsqueda, debates y análisis, que hemos sabido más respecto de las significaciones que los niños construyen, develan u ocultan respecto a sus escuelas, al trato cotidiano o al trato hacia sus familias. Pero hemos conocido mucho más desde el habla adulta, de las representaciones y significados que la comunidad educativa tiene sobre los niños llegados a las escuelas. Sin duda estamos ante un habla contradictoria, plagada de prejuicios y temores, pero que debe tratarse con el cuidado que corresponde a una construcción que los supera, que forma parte de la institución escolar, que está presente en la sociedad chilena y que día a día escuchamos y leemos como si formara parte del paisaje nacional. Son los niños hijos de inmigrantes quienes padecen directamente de esta construcción negada que los afecta y los conforma como inmigrantes, sin serlo y siéndolo al mismo tiempo.

La inmigración en Chile no es cuestión nueva. Su historia proviene de la constitución de la nación chilena durante los períodos de consolidación del progreso a la europea que precisaba de un desarrollo blanco. Al igual que otros países latinoamericanos, nuestro país presenta procesos de 
conformación nacional construidos en categorías raciales donde lo blancoeuropeo deviene un elemento central, tanto para definir simbólicamente a la nación, como para afirmar la distinción entre clases sociales y posiciones de poder. El racismo y la discriminación por lo tanto, no pueden entenderse por fuera del nacionalismo cuando se trata de examinar los procesos históricos de formación del Estado-nación. Los Estados siempre luchan por la apropiación del territorio con el objetivo de controlar las poblaciones y producir una comunidad política que supere las divisiones de clase. En este caso, la voluntad de esta política se arraiga en valores raciales que requieren a un otro que represente la alteridad negada frente a lo blanco de un imaginario europeo que se convierte en condición para la transformación social.

En América Latina y en Chile esta alteridad se ha personificado en la figura del indio y del negro que debe ser conquistado o aniquilado. En nuestro país, durante el siglo XIX, este otro convertido en enemigo se ubicaba en el sur y se forjaba en la guerra contra el colonizador; hecho producido en un momento de higienización y de blanqueamiento, característicos de los procesos modernizadores ligados a políticas de migración selectiva destinadas a inmigrantes europeos que vinieron a poblar las tierras del sur. Por el norte del país, esta misma ideología selectiva se reafirmó durante y sobre todo después de la Guerra de Pacífico, con el violento proceso de chilenización protagonizado por las Ligas Patrióticas (González, 2004) que reprimieron salvajemente a los peruanos, marcando para siempre al norte de Chile. En Tarapacá, los peruanos no calificaban como ciudadanos: sus casas fueron marcadas, sus familias perseguidas, expulsadas o asesinadas.

Si bien durante el período fuerte de la industrialización no se observaron grandes flujos migratorios provenientes del extranjero, dado que las migraciones fueron internas y estuvieron protagonizadas por una masa importante de población trabajadora campesina que emigró a las principales capitales del país en busca de trabajo, el concepto de raza y la necesidad de mejorarla seguirían operando. Como menciona Subercaseaux (2007: 32) varios problemas de la época, como la salud, la educación, la mortalidad infantil y el alcoholismo, fueron entendidos como problemas ligados a una raza que era preciso extirpar bajo la utopía de su mejoramiento. Pero además, el mismo autor advierte que la categoría de raza chilena, entendida como base étnica de la nación, no es más que una invención intelectual, una representación sin fundamento objetivo, un significante vacío que puede ser llenado con rasgos biológicos, síquicos, culturales o sociales. Podríamos entenderla como una invención emocional que obedece a una lógica no científica y más bien cercana a las zonas oscuras y misteriosas del nacionalismo y de la religión que a la del conocimiento racional y empírico. Su verdad por lo tanto, no depende de un referente objetivo sino de la emocionalidad que subyace a ella.

Durante el régimen cívico militar, una oleada de emigración se produjo por la persecución política y los problemas económicos derivados de la dictadura. En 1975, se establece el Decreto Ley No. 1.094 y en el año 
1984 el Reglamento de Extranjería, conocido como Ley de extranjería ${ }^{2}$ que rige aunque con algunas modificaciones, hasta hoy (Mezzano, 1995). Como destaca Stefoni (2003), esta normativa tuvo una fuerte orientación policial centrada principalmente en el control de fronteras para evitar la entrada de elementos peligrosos o terroristas que amenazaran la estabilidad nacional, cuestión que enfatizaba el carácter selectivo de una ley que reforzaba la noción de seguridad nacional y territorial.

Desde los años noventa, se producen a nivel mundial importantes desplazamientos migratorios como producto de las crisis del capitalismo que incluyen a América Latina. Pero Chile vive a comienzos de esa década una situación particular vinculada al fin de la dictadura y la apertura económica, que lo llevará a ser uno de los países elegidos por los inmigrantes latinoamericanos para llegar. Según datos del año 2009, el 73\% que hasta ese momento llegaban a Chile eran sudamericanos y el 61\% provenía de países fronterizos: Perú, Argentina y Bolivia. Actualmente, la población peruana es la más numerosa con un 37,1\% habitantes en el país (Departamento de Extranjería y Migraciones, 2010). Pero hay que dejar en claro que las características de estas migraciones distan mucho de las de los europeos a los que hicimos mención, por las razones y condiciones para migrar, por el origen de sus protagonistas y por el modo en que se involucra el Estado en dicho proceso.

Otros inmigrantes llegados a Chile en condiciones similares, como los argentinos por ejemplo, no han sido percibidos como inmigrantes ${ }^{3}$, mostrando que la percepción de la migración como un problema no se basa necesariamente en hechos concretos y su raíz puede encontrarse en prejuicios, estereotipos y temores a la inmigración y a ciertos inmigrantes respecto de otros. En suma, el inmigrante puede entenderse como una producción de problemas externos, de situaciones que se le escapan y de discursos que lo clausuran para legitimar una condición negativa. Su estatus tiene aristas sociales, jurídicas, políticas y también científicas (Sayad, 2006) que lo hacen existir a partir de los problemas con los que se le vincula.

No obstante, el inmigrante es esencialmente fuerza de trabajo provisorio, en tránsito, revocable y reemplazable, que hace a la acogida simultáneamente cínica y problemática. Cínica, pues públicamente se ostenta amabilidad frente al forastero descrito en general, obviando detenerse es el inmigrante real que perturba el orden de la interacción normal de la vida. Problemática, pues el que llega podrá ser huésped durante un tiempo, pero su condición provisoria le reserva una vida de dificultades. Entonces todo devendrá provisorio. En este marco complejo, los niños vivirán entre una sociedad de acogida que no los acoge y una sociedad de origen que tampoco los reconocerá como peruanos propiamente tales, dado que presentan una condición de inmigrante heredada e incompleta. Sufren las consecuencias de la inmigración de sus padres, enmarcada en las condiciones generales de los procesos migratorios protagonizados por un universo de pobres, que responden a crisis mundiales y que hacen estallar los modos de vida de las sociedades, y en particular, a sus familias y vivencias cotidianas. 
La percepción que hoy tienen los chilenos de la inmigración y de los inmigrantes es muy distinta dependiendo de quien se trate. La mirada hacia la migración peruana es negativa y al igual que sus padres, los hijos de inmigrantes peruanos que abordamos en este trabajo enfrentan la violencia racista y xenófoba. Es así como inmigrante no es palabra que refiera a todos los de dicha condición, sino a quienes develan la inmigración como estigma construido; es decir, a los que traen a cuestas lo indígena o lo negro.

A la deficiente inserción laboral de los padres y la precariedad que caracterizan sus empleos -aun cuando presentan buenos niveles de conocimiento-, se agregan obstáculos puestos por las instituciones que no están informadas ni formadas sobre sus características socio-culturales y la necesidad de una acogida que les ayude a organizar sus vidas. Por otra parte, los niños heredan las humillaciones y los maltratos vinculados a su origen y al origen de sus padres, es decir, un racismo que probablemente se prolongue en el tiempo bajo denominaciones que colocan a las generaciones de inmigrantes en un lugar preponderante.

\title{
La mirada de la comunidad educativa: ¿racismo consciente $y / 0$ no consciente?
}

\begin{abstract}
“Cuándo peruano se transformó en una mala palabra, la niña se queda desarmada, no tiene palabras. Ella sabe que está aludiendo a algo incómodo y ha aprendido que, que es como feo hacerle notar al otro que viene de otro país, pero no tiene muy claro ni por qué, ni qué de lo que dijo está mal, ¿me entiende? los dicen por hueviar son niños, no tienen el control. Más grande saben que están haciendo daño, pero chicos Hay un grupo que se dicen nosotros, y hay un grupo al que se le llama otros, y por alguna razón eso no está bien, o por alguna razón, eso molesta. Por ahí por quinto, sexto, ellos empiezan a sentir odiosidad por eso, por ese otro, porque empiezas a entender otros/nosotros”. (Entrevista Ps.)
\end{abstract}

Damos cuenta de las consideraciones de los adultos respecto a los niños que llegan a las escuelas y que contradictoriamente los caracterizan, sea negativamente, sea positivamente. Hemos encontrado directores un tanto más preocupados por conocer las culturas de los niños y desentrañar lo que traen de sus familias y cercanos, y hemos entrevistado directores cuya buena voluntad de acogida pretende la asimilación, señalando que sus escuelas: son escuelas chilenas donde no se hacen diferencias, pues todos los niños son iguales. Hemos escuchado a psicólogos, profesores e inspectores que los describen empequeñeciendo sus orígenes y sus nombres o retratándolos para mostrarlos a sus amigos. Los reciben con sospecha y se burlan de la forma de sus cuerpos y de sus costumbres. Lo que hemos escuchado sin embargo, no difiere de lo que oímos en las calles y en las reuniones familiares, son las repeticiones de un sentir común que en la cotidianidad se devela como actos, discursos e ideología racista, y que no se reconocen 
como tales pues surgen en la vida diaria, como algo normal.

Y aunque la mayoría de estas evaluaciones son las mismas que sufren los niños descapitalizados por sus pobrezas, los hijos de inmigrantes peruanos se ven particularmente afectados pues se los destaca cruelmente, como culpables de un modo de ser proveniente de su origen. Por razones que hemos dado antes, relativas a esta extranjeridad negada de inmigrantes que se arraigan cultural e históricamente en el castigo, no siempre podemos explicar estas situaciones desde un problema de clase social, ya que no siempre la pobreza explica el trato dado a los ciudadanos peruanos que residen en Chile. Un estudio reciente ha demostrado que inmigrantes peruanos con trayectorias laborales ascendentes, han sido también objeto de racismo y xenofobia (Mora y Tijoux, 2011). Por lo tanto si bien raza y clase se entremezclan, pensamos que hay que buscar las respuestas en los problemas raciales de la construcción de la nación chilena.

Las escuelas donde se llevó a cabo esta investigación, están emplazadas en sectores marginados de los barrios céntricos de Santiago, ya segregados desde mediados del siglo XX, donde han vivido en distintos momentos inmigrantes rurales de la industrialización, familias de excluidos, trabajadores y estudiantes precarios. Desde los años noventa se han transformado en barrios de inmigrantes percibidos negativamente, considerados peligrosos por la presencia de esta alteridad que surge de una otredad negada. Son sectores evitados, donde abundan casonas, cités y conventillos, alquilados por pieza a bajo precio y que producen altas ganancias para arrendadores y subarrendadores inescrupulosos. Los inmigrantes deben residir con familiares o cercanos en viejas habitaciones nunca refaccionadas, oscuras, heladas, peligrosas, que carecen de servicios higiénicos y donde generalmente un único baño se comparte.

"Suponte que esta pieza vale 40 mil pesos para arrendarla, y ellos cobran 80. Entonces sí entiendo. Eso es un abuso, eso es una sinvergüenzura porque como no hay más... Entonces le cobran el doble de lo que tienen que pagar porque la gente por aquí paga 80 mil pesos por una ruca”. (Entrevista D.)

"Por aquí las casas son de dos piezas, también tenemos alumnos, cachai, una pieza, y el living comedor y la cocina y el baño, ¿dónde tienden cuando lavan? es algo que yo todavía no me explico, a lo cual nunca le he encontrado una explicación. Igual si tú veis hay hartas casetas de Seguridad Ciudadana y todo por acá. (Entrevista Ps.)”

Sabemos que estas son las condiciones para los migrantes en el mundo y sabemos también que intentar vivir allí es fuente de distintos problemas, pero también sabemos que son similares a las que viven personas del universo empobrecido cuando deben salir de sus tierras para buscar trabajo. Solo que en esta investigación se develan como problemas propios de los peruanos, que según los profesores entrevistados tienen un cierto tipo de 
vida. Los hijos de estos inmigrantes, sin buscarlo, quedan vestidos de una condición especial y espacial: ser hijos de la inmigración como problema arraigado en la pobreza de su clase social y portar la extranjeridad de un país que provoca resquemor y crítica. A partir de esta doble negación, todas las acciones familiares o individuales serán evaluadas negativamente.

Desde los años noventa, llegó un mayor número de inmigrantes peruanos a Santiago, atraídos por las posibilidades laborales en Chile y empujados por las crisis económicas y políticas del Perú. Eran principalmente mujeres y trabajadores jóvenes. No llegaban muchos niños, los más pequeños permanecían en el Perú y los más grandes intentaban entrar al mundo laboral. Eran trabajadores que buscaban sobrevivir y que se insertaban en trabajos precarios, con vidas que se transformaron y con ellas sus relaciones sociales, cambiando el modo de ser familiar al que estaban habituados.

“La inmigración en Chile no apareció nunca como un problema, porque la primera oleada de inmigrantes, no eran inmigrantes problemáticos”. (Entrevista D.)

"Ellos vienen con ese tipo de vida, de todo, po, imagínate que los papás se vienen primero ellos, después traen a los hijos, a los dos, tres años, cuatro años, cinco años, en realidad uno no sabe, pero los primero niños que llegaron extranjeros eran de tres años, cuatro años, abandonados por sus padres en Perú. Después empezó como a cambiar la cosa y ya ahora, por ejemplo, la mamá se viene un año y ya al otro año se trae al hijo, pero antes tres, cuatro, cinco años. () Nosotros tuvimos niños de 6 años que quedaron solos, solos, que los veía una vecina de más allá, que era también peruana que vivía en una pieza. Pero para nosotros es vivir solo. El hecho que el niño estuviera solo en una pieza para nosotros es vivir solo, sin su mamá, sin su papá”. (Entrevista Ps.)

Algunos años después del inicio del nuevo siglo, cuando los niños nacieron en Chile o ingresaron con más frecuencia a las escuelas, fueron vistos como sujetos de la migración peruana, que, como dijimos, permitieron la continuidad de establecimientos que por la oferta del mercado escolar peligraban cerrar. Por razones económicas, estos hijos de inmigrantes ingresaron a las escuelas municipalizadas, enfrentándose a obligaciones administrativas no siempre simples de resolver y donde algunos quedaron y aun quedan excluidos, aunque puedan estar en las escuelas (Colectivo Sin Fronteras, 2004). No obstante al llenar los cupos que se habían vaciado, se convirtieron en niños útiles para la institución.

“El año 2002 fue el boom de los niños extranjeros que empezaron a ingresar a la escuela y después cada año era más y más y más hasta, hasta ahora que son más de la mitad, más () Porque que te llegue un niño extranjero aunque sea indocumentado es trabajo que tú tienes seguro y que en realidad la escuela no se va a morir, porque siempre nos estuvieron amenazando que la escuela la iban a cerrar () Enton- 
ces el Director hizo como una campaña con los niños extranjeros y empezó a darle información y se empezaron a recibir. Pero yo creo que es más para eso, para matrículas. En realidad, si tú lo miras así fue por eso, porque no teníamos matrículas”. (Entrevista S.).

...le digo saque su carnet hijo, tía, no tengo plata, tía, tengo problemas con el consulado, tengo que pagar 120.000 pesos en el consulado para que me entreguen el papelito. Tengo que pagar 80.000 no sé a dónde, tengo que pagar cuánto más, y como el niño no tiene carnet chileno, por supuesto que no aparece en ninguna acta a final de año, como no tiene Rut, no aparece, y después hay que hacer todo un proceso engorroso”. (Entrevista D.)

"Ha cambiado harto, gracias no sé a quién, ha cambiado el sistema de vida entre los niños extranjeros y en realidad a nosotros nos gusta, nos gusta, nos gusta que hayan niños extranjeros por el hecho de que la cultura que se produce es diferente”. (Entrevista S.)

La llegada de los hijos de inmigrantes puede ser más o menos apreciada y al igual que los sectores del barrio donde habitan, sus escuelas advierten de situaciones de poder, segregación y diferenciación y, cuando aumenta en número, los espacios se transforman y adquieren características multiculturales que la comunidad educativa puede o no considerar para una vida cotidiana escolar más abierta y menos belicosa.

"Nosotros del punto de vista valórico o patriótico () seguimos siendo un país que está en Chile, con nuestros valores, eh, respetamos su cultura ¿de qué manera? Bueno le recordamos, hacemos su pequeño acto cuando es la independencia de Perú, cuando hay una actividad ellos traen su propia comida para vender, sus cantantes () Pero estamos en un sistema que es chileno y en base a eso ellos tienen que adaptarse, lo cual para ellos ha sido mucho, muy bueno () un poco con dolor al principio porque han dejado su país, vienen muy apenados pero generalmente se integran () Igual lo acogemos”. (Entrevista D.)

La institución escolar comprende actores entendidos como una pluralidad que converge en múltiples interacciones. Por ello no puede actuar de modo igualitario y distribuye las expectativas individuales de un modo coherente con las posibilidades objetivas que tengan más tarde los niños en el sistema social. Así es como se trabaja por una búsqueda de estatus a partir de valores universalistas que sancionan el éxito a partir de criterios homogéneos y sustituibles. La selección se basa entonces en criterios racionales de competencia. Si todo funciona bien, el niño tendrá el estatus social que se merece. En este marco, se complica el éxito de los hijos de inmigrantes, no solamente por sus dificultades de comprensión en la escuela chilena sino porque además son vistos como niños-problema a partir del carácter, es decir, a partir de desde características personales que nada tienen que ver con su capacidad de aprendizaje. 
“...el alumno peruano sobre todo tiene esta personalidad como bien, en términos domésticos, como paisana. Que se te amurran y se te amurran, no lo sacaste nunca más de ahí, los brazos cruzados, la cara larga, no les corre ni una lágrima, sino que es como la rabia, como el tema rabioso que les entra y todos. Son niños poco comunicativos”. (Entrevista Ps.)

"De que son niños que vienen con los hombros muy bajos, con la mirada muy triste y con la cabecita y la cara como caída. Lo que me imagino, siempre que lo he visto. Llegan como derrotados () Lo estuvimos conversando y hay varios factores que influyen. El clima, el lugar donde están viviendo, el desarraigo de su familia, de sus amistades, de todo y venir a encartarse a un lugar que a lo mejor estás viviendo peor de lo que vivías allá. Que nosotros como chilenos no somos () somos aparentemente cariñosos, pero somos muy aprovechadores”. (Entrevista D.)

Hay que buscar más en los silencios de los niños o en el modo en que se apartan de los grupos cuando son los miembros de una comunidad educativa que critican los lugares donde habitan. Un espacio exiguo para vivir se vuelve condición de peligro y por ello inmediatamente se apela a la vigilancia del sector contra los inmigrantes, hecho que nada tiene que ver con sus situaciones de vida cotidiana. Calificados y clasificados por su origen, aun siendo chilenos, los hijos de inmigrantes no son vistos como un aporte. Ser hijos o hijas de peruanos los hace ser simplemente peruanos entendidos como seres descalificados.

“¡Peruano!, entonces ese es un tipo que no nos aporta absolutamente nada, ¡ni al colegio, ni a nuestra cultura ni a nuestro país!”. (Entrevista P.)

La institución escolar está sumida en una producción de saberes disciplinarios que contienen estrategias de poder similares a las que se producen al interior de las relaciones en las prisiones, los regimientos o los hospitales. Hay en suma, poder de unos y temor de otros y como si fuese un microscopio de la conducta, la escuela busca por una parte domesticar los cuerpos y volverlos dóciles y por otra dominar los espíritus a partir de actividades y prácticas que diferencian, jerarquizan, homogenizan y normalizan los comportamientos (Foucault, 1975). Además del examen, la prueba, los controles que permiten diferenciar, pues clasifican y castigan, uniformizan e individualizan cuando se trata del racismo que en el cuerpo opera directamente, al igual que las emociones.

Los adultos de la comunidad educativa, que tienen la función de acogerlos y facilitar sus existencias al interior de las escuelas, los catalogan por su origen y construyen juicios que el sentido común alberga en el trato cotidiano. La valoración que llevan a cabo se convierte en una constante y contradictoria evaluación de sus comportamientos y presencias, pues bien pueden considerar positivamente el exotismo vinculado a aspectos 
culturales apreciados, como el capital lingüístico o la cocina peruana, o juzgarlo negativamente desvalorizando una su forma de comer o el modo de preparar los alimentos:

“...las comidas, nosotros tenemos totalmente diferente las comidas. Ellos comen todo con ají, todas sus comidas son con ají, nosotros, los niños no comen ají aquí en Chile. Ellos comen comida con ají, no comen legumbres como comemos nosotros, la comen de otra manera. Ellos, como ensalada, nosotros, como plato de fondo. Entonces unos porotos diferentes, las lentejas diferentes, las comidas Imagínate, el pollo lo fríen de otra manera como lo hacemos nosotros. Para ellos fue una costumbre acostumbrarse, adaptarse dentro de la escuela en la comida”. (Entrevista S.)

“...tenemos tres haitianos, niñitos haitianos, dos varones y una dama. Entre ellos, pucha que son lindos, bien negritos, oye. Hermosos sus ojos, tan tímidos que no les gusta la papa, que no le gusta la pata, que no le gusta la carne, que no le gusta la zanahoria, que no le gusta la lechuga, que no le gusta comer ninguna cosa [fue aumentando el tono de voz a lo largo de la frase] P: ¿Y qué les gusta? Puras cochinadas no más. Quieren comer papas fritas. Quieren comer completo porque eso les encantó. Los completos como los hacen aquí, porque en su país tienen la pura tripa dentro la hacen no más”. () (Entrevista D.)

“...La comida es una cuestión cultural, de eso no hay lugar a dudas, ya? Entonces, por ejemplo, en este colegio, se ha hecho en más de una oportunidad la típica completada que se hace, siempre, en vez de hacer completada aquí se hace, pollada. ¿Por qué? Porque los peruanos comen pollada, y los peruanos tienen, y yo lo comento aquí, estas, estas ya empiezan a hacer vivencias que son, no del colegio propiamente tal, vivencias que yo he tenido producto de haber llegado a trabajar acá”. (Entrevista D.)

\begin{abstract}
¿Pero, será posible adaptarse? Si así fuese, esta adaptación es forzada y lo que ven los ojos de estos adultos hacen surgir al cuerpo de los niños como si fuese una frontera, vinculándolo a emociones propias de una cultura y a los afectos que estos pequeños tienen con el lugar de donde provienen sus familias. Entonces los hijos de inmigrantes peruanos portan la extranjeridad como una herencia. Y si bien las escuelas son instituciones supuestamente destinadas a la socialización y a la integración, se evidencia una contradicción que no puede resolverse sin que una política de educación esté destinada a la comunidad educativa misma para evitar que un racismo de características biológicas siga reproduciéndose cotidianamente.
\end{abstract}

“Las niñas son muy tímidas, retraídas la mayoría. Pero son requetecontra-enamoradas desde chiquititas. ¿Por qué? El otro día leyendo supe por qué. Las niñitas a los 12 o 13 años están buenas para casarse. Esa es la mentalidad de ellos, allá. () Ahhh y cómo se 
llama este demonio rojo que antes de indisponerse era más flacuchenta, más espigadita, más estilizada y se indispuso y como que se estiró por todos lados. A mí que se ve así porque se le ha dado por hacer sus pantalones y todas sus cosas bien apretujadas y bien pitillas. Entonces como que se ven más, más chatas”. (Entrevista D.)

"Es un negro muy simpático, es muy agradable él como persona y todo. Tiene un problema, neurológico, entonces, como que las palabras le salen así, enredadas [remeda la voz] y fonoaudiológico además, pero se hace entender bastante bien, si tú te detenís te dai cuenta, oh, algo raro tiene, pero nada que sea así como súper evidente. Es como medio tímido pero simpático a la vez”. (Entrevista Ps.)

El racismo se inscribe en prácticas violentas que pueden darse en miradas de desprecio o de burla, en actos de intolerancia, en gestos humillantes o en actos de explotación, como también en discursos y representaciones que heredan del fantasma de la profilaxis y de la segregación, como necesidad de purificar el yo y el nosotros ante cualquier perspectiva de promiscuidad, mestizaje e invasión articulada en estigmas de la alteridad, organizando sentimientos y confiriéndoles una forma estereotipada. Esta combinación se organiza en una red de configuraciones afectivas que permite atestiguar la formación de una comunidad racista, como si se tratara de un espejo donde los individuos y las colectividades que son el blanco del racismo, están obligados a percibirse como comunidad (Balibar, 1991). El racismo cotidiano constituye una matriz de relaciones e interacciones que reproducen estas prácticas, discursos y representaciones de manera regular y rutinaria, en situaciones cotidianas que consiguen diferenciar los que llegaron antes de los recién llegados y luego poner a funcionar los sentidos, específicamente el olfato en este caso:

“Los niños nacidos acá son los que viven acá ya se han mimetizado mucho, entonces este niño de repente tú no lo diferencias, solamente porque es hermano de fulano de tal, su, sus rasgos, su carita todo podrá ser igual, el color de su piel porque es algo muy especial. Sí usted se diferencia, y es algo que yo no debiera decirlo pero tengo que decirlo como chilena roteca: nosotros los chilenos somos enfermos, enfermos de malacatosos en el sentido de que nuestro olfato es maldito. Tenemos muy buen olfato los chilenos, y sabes que por el olfato podemos identificarlos () Yo tuve la oportunidad, gracias a Dios de salir y olí a uno de los monitores que me tocó con el cual no pude seguir. Yo hago el comentario con mis colegas: ¿sabes qué? yo no puedo seguir en este grupo, cámbiate de grupo me dijo una de ellas. Porque es mestizo, me dijo, y el olor de él tú lo sientes. Es que no aguanto el olor a cebo y eso mismo, palabras textuales de nuestros niños me han dicho de sus compañeros peruanos. El olor que tienen, tía () Son los alimentos. Son nuestros alimentos () nosotros tenemos unos niños de apellido (xxx) y tú te acercabas al niño y su piel olía a pescado: ¿tu madre cocina mucho pescado? Hay gente que vende pescado. Pero no era porque el niño no se bañara, es 
porque comía. () Esa sensibilidad que tenemos en ese aspecto los chilenos, es bien especial, y nuestros chiquillos, aquí en esta escuela felizmente tienen la confianza de decirnos las cosas”. (Entrevista D.)

El racismo, en la medida que se hace cotidiano y se vuelve parte del sentido común, naturaliza la violencia que los adultos terminan considerando prácticas comunes, normales. Los niños entienden el insulto, a pesar de lo que señala el siguiente entrevistado, pues se dirigen a él para denunciar. En todo caso el insulto parece justificarse ante el desorden del niño:

“...como toda cosa hay ofensas que hasta ellos mismos a veces no las entienden, dicen oiga me llamó peruano, pero si eres peruano ¿para qué, por qué te molesta? o dicen me llamó negro, son todos morenos ¿ya? Cosas así, pero no pasan más allá, o sea, no es una molestia constante. Y ese niño que recibió ese calificativo generalmente es un niño que también es desordenado, o sea también, pero no para que lo hagan una discriminación”. (Entrevista D.)

Los padres peruanos son culpabilizados cuando el niño presenta problemas de conducta como si se tratase de una herencia que se manifiesta de todos modos como comportamiento peruano, a pesar de tratarse de hechos comunes producidos en las escuelas. La madre es como el hijo si lo defiende y el trabajo de los profesores frente a ellos es argumentado como rol formador:

"tenemos por ejemplo un negrito que es del terror, del terror y cuesta mucho manejarlo porque viene la mamá y le presta ropa, le presta ropa, en vulgar chileno y yo digo: Claro si la tiene de los cocos (), ¿cachai? La mamá no va a decir nada, la mamá siempre va a encontrar que todo lo que él hace es el descueve (...) Conversamos eso con el director, y utilizamos otra estrategia con él, ¿cachai? Entonces eso ha funcionado y ha modificado mucho su conducta, está muy bien ahora a lo que era () Porque a nosotros no nos sirve, ¿cachai? mantener a un niño que no se adapta dentro del curso, que es solo. No, no puede ser, porque ahí no estamos cumpliendo el rol formador de la escuela. Si nosotros lo tenemos que preparar para estar en sociedad ¿cachai? Y en eso, como el ensayo, el laboratorio de la sociedad es el curso y si no puede estar ahí, no, y no tiene ningún problema que lo inhabilite, entonces no, estamos mal”. (Entrevista Ps.) origen:

Los niños devienen fuente plural de problemas derivados de un

"Por ejemplo déficit atencionales, problemas de aprendimiento, flojera, malos hábitos, todas esas conductas que no están bien trabajadas () iproblemas de estudio pues! Por ejemplo niños que no estudian () yo soy profesor jefe () tengo una cantidad enorme de niños extranjeros, peruanos, y lamentablemente tengo la sensación de que ellos al llegar a Chile copiaron los modelos equivocados las malas 
costumbres y además de eso son niños que no producen nada, son flojos. () ¿Y qué pasa con el hacinamiento? Pasa de todo pué, desde que los padres beben no cierto, y los niños te comentan a ti: profe estuvimos de fiesta ayer hasta tarde mi papá se curó, mi tío también. Los peruanos llegan todo el fin de semana y se curan ahí, después los chicos, los niños están también ahí, ellos lo ven, en ese aspecto es media nefasta la situación, ahí no es positivo el ambiente, por eso están en un ambiente de riesgo, ¿me entiende? () no tienen desarrollados los procesos propios de lo que es el sistema educativo por lo tanto no tienen el hábito de estudio, les cuesta mucho aprender por lo tanto se pierden en el espacio y se dedican a hacer otras tonteras”. (Entrevista P.)

Los hijos de inmigrantes escuchan y aprenden palabras sobre las cuales fabrican el sentido, combinando lo que perciben desde el uso y la traducción aproximativa de una etiqueta desprendida de sus formas familiares. Si la palabra o el significante son convencionales, los atributos que conforman los conceptos precisan ser aclarados, pues en cualquier lengua, los enunciados deben poder ser traducidos porque al pasar de una forma de hablar a otra, incluso siendo el español la misma lengua hablada, el acento, la tonalidad, la rapidez o la pronunciación, son distintas. Pero también son distintos los sentidos otorgados. El español se habla como chileno, como peruano, argentino, etc. De ahí que las palabras necesiten de una etapa de traducción, dado que en ellas interfiere el bagaje cultural. Pero este es un ejercicio complejo cuando se da en un medio diferente al marco espacial y humano aprendido y que permite significar lo que se dice por ejemplo, sobre cosas que no significan lo mismo o bien tienen usos diferenciados. En la escuela, hay costumbre en torno a ciertas órdenes que se dan a los niños o en formas de enseñar que varían de un país al otro y entonces la comprensión que tienen los hijos de inmigrantes se puede ver afectada.

“...lo discriminan y le dicen peruano, peruano acá, peruano allá. Si claro, son cosas que se dicen. Son cosas que los niños les dicen. Pero igual es un lenguaje que están construyendo entre dos. Entonces, ehhh () sería más cuidadoso a la hora de bajar la mirada, analizar e interpretar lo que dicen los niños. Hay cosas que dicen en la casa que significan esas diferencias de origen, de nacionalidad y discriminación () pero, pero también hay un lenguaje construido por ellos. Donde, donde no quieren decir lo que nosotros estamos entendiendo. También vimos al niño peruano, una niña peruana diciéndole un montón cosas al otro, como que van armando un lenguaje hasta que finalmente lo moldean y lo suavizan porque empiezan a cachar que hace daño, o uno se puede meter y lo van bajando y en fin, me he encontrado con que de repente le devuelve un niño como lo que te contaba atrás, que me dice disculpe la palabra, pero, pero parece peruano”. (Entrevista Ps).

Los profesores se extrañan de esta incomprensión que detectan como flojera, ligada obviamente a lo salvaje de países desde antes desconsidera- 
dos y descalificados. La lengua escolar es una lengua normada y legitimada y los modos de hablar de todos los niños deben adaptarse a ella. Todo lo que se escapa de esta reglamentación, es evaluado negativamente por los profesores. Sin embargo, no por ello los hijos de inmigrantes carecen del manejo del pensamiento y de la reflexión. Aunque no hemos trabajado en las aulas y nos abocamos a la observación de los espacios de juego, de encuentro y de llegadas y salidas a los establecimientos, hemos visto como las correcciones del estilo de hablar o las burlas por los modismos peruanos, entraban perfectamente en lo que explicamos respecto al manejo de un capital lingüístico que, en este caso, debe ser el modo de hablar y de escribir chileno y por tanto los hijos de inmigrantes son percibidos como niños deficientes. Pero hay signos de apertura y de búsqueda comprensiva, debido al tiempo en que los hijos de inmigrantes han permanecido en la escuela y los capitales que han traído y difundido:

"Fíjate tú lo siguiente, los peruanos al igual que los chilenos hablamos español, unos con un cantito, y otros con otro. La religión, los que son de religión católica, la mayoría católico, que se casan por la iglesia, que bautizan, que hacen esto, que hacen esto otro. ¿En qué se empiezan a diferenciar? En giro idiomático, ¿ya? Giro idiomático, como el coger, el jalar que son los términos más usuales. La bolita para nosotros los chilenos, para ellos son las canicas, pero que los niños los asumen como una cosa absolutamente natural. Entonces yo creo que ahí, que mucho, por ejemplo en el colegio, se van incorporando este tipo de cosas”. (Entrevista D.)

\section{A modo de conclusión}

El material empírico que entregamos en el acápite anterior es solo una parte de lo que hemos recogido, y las citas escogidas entregan parcialmente el sentir de los adultos entrevistados y fragmentos de lo que acontece cotidianamente en las cuatro escuelas abordadas. Hemos privilegiado la palabra de estas personas por la fuerza que tiene su objetivación. Pero también hemos debido recortarla por la extensión de este trabajo. Sin embargo podríamos, a la manera de Bourdieu, entregarlas más adelante, como relatos completos que permitirían al lector ingresar de mejor modo a un ejercicio comprensivo de esta parte de la miseria de un mundo (Bourdieu, 1993) que devela sufrimientos sociales repetidos, que no aparecen en la inquietud de la política contingente ni en las preocupaciones periodísticas, salvo cuando un inmigrante protagoniza actos delictivos o es sospechoso de algún conflicto. Cuando se amalgama la inmigración a la delincuencia, desaparece el nombre y el apellido del acusado y más que nunca existe solo por su origen. Los hechos aludidos son los que se dan en la vida cotidiana, como lo advierte Goffman en su tesis respecto a lo que ocurre con las obligaciones entre las personas cuando se cruzan, caminan o se saludan. Todos actos pequeños dados hacia la sociedad, toda una sintaxis del orden de la interacción solo coherente e inmanente cuando los individuos aseguran entre sí una interdependencia que reposa en el reparto de las mismas creencias (Goffman, 1988: 197). Cuando estas creencias no se comparten, no se sa- 
tisfacen las expectativas de quienes manejan la situación, el lugar o el territorio. Sin reciprocidad, la vida cotidiana queda interrumpida. El inmigrante peruano irrumpe en las rutinas de la vida cotidiana chilena de un modo negativo, contrario por ejemplo a lo que ocurre con el turista.

Comprender la violencia de estos sufrimientos que enfrentan los inmigrantes peruanos en Chile, implica ingresar en el racismo como una categoría productiva que no aborda el fenómeno como algo nuevo, sino como algo histórico, pero tampoco como un hecho coyuntural, sino como un hecho estructural. En Chile el racismo no ha sido muy trabajado y se le menciona priorizando otras categorías, menos duras, como la discriminación proveniente las representaciones, los estereotipos o los prejuicios. Tal vez porque referir al racismo en Chile es visto como un acto políticamente incorrecto y por eso su negación (yo no soy racista, pero). Pero los hechos que organizan estereotipos y prejuicios están en alguna parte. Principalmente en la construcción de estigma sobre el inmigrante peruano, anclado en una ideología de carácter racista. Entendemos al racismo como una construcción ideológica, institucionalizada en políticas migratorias específicas y como una formación de carácter histórico y estructural. De ahí la importancia de abordarlo en su relación con un proceso histórico de construcción nacional, desde la formación de la identidad chilena, en una cultura donde se configura a un otro. El racismo no solo es una ideología exterior a los sujetos pues se ancla en discursos y prácticas de la interacción cotidiana y visto desde esta dimensión relacional, incluye dos partes que establecen un juego que requiere del sujeto racista como del sujeto-objeto del racismo.

Y estos sujetos-objetos del racismo, en este caso, son los hijos de inmigrantes peruanos por parte de una comunidad educativa que supuestamente entre sus múltiples funciones, debe educar contra el racismo. Es difícil imaginar una educación cívica que no lo considere en sus programas o que solo lo haga para cumplir y tratar los contenidos. Ejercitar esta educación es algo muy distinto cuando deben ponerse en práctica los elementos que dichos contenidos tienen como efecto y como prevención en la vida cotidiana. El racismo reviste muchas formas dadas en prácticas y en discursos desde fundamentos religiosos sobre el bien y el mal y desde fundamentos políticos de la igualdad que pierden sentido, especialmente cuando la diversidad cultural aparece como solución de los problemas. Esta diversidad es un maquillaje que no resuelve la violencia de los sufrimientos si se presenta únicamente como una feria cultural, donde cada grupo expone por separado sus productos, generalmente servidos o contados por quienes los representan, por sus cuerpos mismos, sus rasgos, lenguas, gestos y modos de hablar, que hace a los visitantes mejor servidos, o cuando se trabaja de vez en cuando en reuniones educativas de las escuelas donde la corrección ante el grupo predomina. El discurso moralizador es socialmente correcto, pero no cambia los habitus y por lo tanto no toca las estructuras más profundas en donde se cobija la violencia contra una extranjeridad que parece peligrosa, aun cuando se trata de niños hijos de inmigrantes, pero también de alumnos cuyas familias buscan a la escuela como cualquier familia que ve a la educación como un valor universal. 
Tener éxito en la escuela en las actuales condiciones de competencia, es ya un problema para cualquiera y por ello la escolarización de los hijos de inmigrantes no puede verse en perspectiva comparada. Por una parte, la clase social juega desfavorablemente cuando estos niños carecen de los capitales que le permiten competir en el campo escolar y además, su condición de hijos de inmigrantes peruanos los pone en un lugar difícil para la evaluación de sus escuelas. A pesar de la inserción que ésta les ofrece, el haberse socializado en barrios de inmigrantes puede complicarlos, especialmente si han enfrentado el racismo hacia sus familias o hacia ellos que termina por cristalizarse en los cuerpos y arraigarse en sus sentimientos, como un hándicap para la competencia escolar y la carrera por un empleo estable (Beaud, 2002). El barrio o el sector donde habitan los identifican y los nombran ${ }^{4}$, además de señalar su clase social y provocar evaluaciones de su persona. Este es un problema insoslayable, porque las escuelas están ubicadas en sectores marginados de la ciudad que son escenarios privilegiados de las diferencias, las quejas y las denuncias. Sus comportamientos son incomprensibles para los chilenos con los que comparten una vida cotidiana extremadamente cercana, entonces los evitan o simplemente se van del lugar. Así es como la relación entre chilenos y familias de inmigrantes se produce en términos de dominación, apoyada en la ley y en una vigilancia permanente. Tal como lo explica la tradición de Chicago, en la ciudad se articulan el espacio urbano, las posiciones sociales y las relaciones interétnicas. Las reacciones de rechazo, de indiferencia y de solidaridad se revelan necesariamente en torno a cuestiones económicas y las interacciones dan cuenta de realidades que se dan en inmigrantes concretos, diferenciados por nacionalidad, sexo, clase, edad y trayectorias de inmigración ${ }^{5}$. Los conflictos, más que consecuencias de una desviación social, corresponden al clásico proceso descrito por la escuela de Chicago, que implica el ejercicio de apropiación de oportunidades, donde el espacio público deviene rápidamente espacio político que deja fuera la organización de los habitantes quienes finalmente deben arreglar sus problemas como pueden.

Los entrevistados nos han hablado largamente de los barrios de las escuelas, de sus historias de segregación, de las dificultades del hacinamiento y de construcciones inseguras, pero principalmente de la lejanía del Estado. En este marco y en barrios que pueden todavía como barrios antiguos, con características de encuentros de vecindario, la escuela es un eje de encuentros que podrían ser mayormente trabajados con vistas a la inserción de los inmigrantes y especialmente de los hijos de inmigrantes que ya participan en las escuelas. Con esto no pretendemos decir que los problemas se resuelvan, sino que tal vez solo puedan comenzar a ser reflexionados al interior de los lugares mismos donde se producen, al mismo tiempo que se analicen en una comunidad educativa y académica que entregue propuestas al Estado.

Los niños y las niñas que protagonizan este estudio se intentan ajustar a una realidad social que consideran suya, pero que se ha transformado con sus presencias. Estos problemas que pueden ser analizados comprensi- 
vamente desde las interacciones de una vida cotidiana escolar rutinaria, no pueden ser respondidos completamente desde este enfoque. Es preciso apelar a la constitución de la nación chilena y al interés del Estado por someterlos a procesos de homogenización nacional y de uniformización social en donde la escuela participa. Pero hay una disociación entre la función de integración que tiene el Estado y las lógicas de diferenciación de un mercado en donde está presente el mercado escolar. Esta diferenciación necesita de nuevas leyes y de nuevas reglamentaciones que no sigan apartando a los nacionales de los inmigrantes tal como sucede hoy en Estados Unidosmás aun cuando Chile se vuelve país de interés para otros inmigrantes que actualmente ingresan y que caracterizados como recién llegados, nuevamente entran en la comparación esta vez entre inmigrantes. Las migraciones internacionales se intensificarán con las crisis económicas que experimenta el capitalismo y aunque pensemos que es únicamente la búsqueda de trabajo la que explica estos desplazamientos, será necesario buscar otras causas, otras dificultades y otras categorías.

En vistas de lo entregado, el combate contra el racismo es necesario, pero es una lucha compleja y delicada que penetra en lo íntimo, en lo oculto y no confesable de las personas, haciendo emanar sentimientos y emociones trastocadas con la llegada de otros que históricamente les han sido enseñados y señalados como inferiores o enemigos. Temores, miedos, rabias, frustraciones y envidias brotan sin que puedan frenarse desde un acto racional. Sigue siendo problemático entonces el lazo con un otro ubicado y sentido más abajo del nosotros.

Por ahora no solo hay que denunciar el que los hijos de inmigrantes se conviertan en chivos expiatorios de las frustraciones de una comunidad educativa. Hay que trabajar para buscar en el sistema educativo mismo y por lo tanto en las instituciones y en el Estado, dicha construcción. Si están menos protegidos por las leyes, se convierten rápidamente en los sospechosos que terminan calmando la sed colectiva que busca terminar con un mal exteriorizado, encarnado, separado del nosotros (Memmi, 1994: 79). Hay que evitar toda destrucción venida de la idea del Bien ubicado en lo nacional, como si nunca fuéramos culpables de nada en una exigencia incansable de pureza y deber ser chileno. Deseo profiláctico y fóbico que termina con el encierro en la casa, los oídos cubiertos y la nariz envuelta en un aroma conocido que evite sentir el olor a extranjeridad. Los hijos de inmigrantes deben seguir bailando a su ritmo y cantando lo suyo aun cuando no sean nunca más ni de allá ni de acá. 


\section{Notas}

${ }^{1}$ Agradecimientos a FONDECYT: El presente artículo proviene de la investigación de la que soy Investigadora Responsable. No 1110059 Vida cotidiana de niñas y niños hijos de inmigrantes peruanos en los espacios sociales escolares: capitales, tácticas y estrategias para la integración en Chile.

${ }^{2}$ Decreto Ley 1094: Establece normas sobre extranjeros en Chile. Publicado en el D.O. N ${ }^{\circ}$ 29.208 de 19 de Julio de 1975. Por ejemplo en su Artículo 15 prohíbe el ingreso al país de los siguientes extranjeros: 1 . Los que se propaguen o fomenten de palabra o por escrito o por otro cualquier otro medio, doctrinas que tiendan a destruir o alterar por la violencia, el orden social del país o su sistema de gobierno, los que estén sindicados o tengan reputación de ser agitadores o activistas de tales doctrinas y, en general, los que ejecuten hechos que las leyes chilenas califiquen de delito contra la seguridad exterior, la soberanía nacional, la seguridad interior o el orden público del país y los que realicen actos contrarios a los intereses de Chile o constituyan un peligro para el Estado.

${ }^{3}$ A modo de ejemplo vale citar el intenso debate de los años noventa que situaba en distintos medios de comunicación a los peruanos como la población mayoritaria y problemática de inmigrantes dentro de Chile siendo, sin embargo, la población argentina la que representaba mayor porcentaje. Según datos del Censo del año 2002, al descomponer la población inmigrante por país de origen se observa que del 68\% de migrantes sudamericanos, los argentinos representaban el 26\% y los peruanos el 21\% según Martínez 2003). Actualmente, la comunidad argentina ocupa el segundo lugar con un 17,2\% de habitantes en el país (DEM, 2010).

${ }^{4}$ Se puede ser nombrado por un barrio y existir por el nombre de una población (soy de: Recoleta, Independencia, La Pintana, etc).

${ }^{5}$ Lo que puede observarse en Chile en barrios ya reconocidos como de inmigrantes: barrio chino, barrio turco, por ejemplo que aluden a sectores del comercio protagonizado por inmigrantes llegados antes. 


\section{Bibliografía}

Balibar, E. y Wallerstein E. (1991), Raza, nación y clase. Editorial Iepala, Madrid.

Beaud, S. (2002), 80\% au bac. Et apres?... Les enfants de la démocratisation, Ed. La Découverte, Paris.

Bourdieu, P. Passeron, J C (1995), La Reproducción. Elementos para una teoría del sistema de enseñanza. Ed. Laia, Barcelona.

Colectivo Sin Fronteras (2007), Niños y Niñas Migrantes: Políticas Públicas, Integración e Interculturalidad, Editorial Quimantú, Santiago.

Cortez, A. (2004), “Integración de los niños y niñas inmigrantes al sistema escolar chileno: obstáculos y desafíos”, en Niños y niñas inmigrantes en Chile: derechos y realidades. Colectivo Sin Fronteras. Ed. Colectivo Sin Fronteras-Fundación Anide-KinderNotHilfe. pp. 163-72, Santiago de Chile.

Foucault, M. (1975), Vigilar y castigar. El nacimiento de la prisión. Ed. Siglo XXI, Madrid.

Goffman, E. (1988), “Lordre de linteraction”, en Les moments et leurs hommes, Ed. Minuit, París.

Goffman, E. (1973), La mise en scène de la vie quotidienne, tomo 1: La présentation de soi, Minuit, Paris.

González, Sergio (2004), El dios cautivo. Las Ligas Patrióticas en la chilenización compulsiva de Tarapacá (1910-1922), LOM Ediciones, Santiago.

Hevia, P. (2009), Niños inmigrantes peruanos en la escuela chilena. Memoria Antropología Social, Universidad de Chile, Santiago.

Larraín, J. (1997), “Modernidad e identidad en América Latina”, Revista Universum, http://universum.utalca.cl/contenido/index-97/larrain.html

Mauss, Marcel (1971), “Ensayo sobre el don”, en Antropología y Sociología, Madrid.

Memmi, A. (1994), Le racisme, Ed. Gallimard, París.

Mora, C.; Tijoux, Me. (2011), Proyecto Fondecyt Trayectorias laborales de los inmigrantes peruanos en Chile: Estrategias de estructuración de la movilidad laboral ascendente. Santiago.

Moro, M. (2002), Enfants dici venus dailleurs. Naître et grandir en France. Ed. La Découverte. Paris. 
Pavez, I. (2010), “Los derechos de las niñas y los niños peruanos en Chile. La infancia como un nuevo actor migratorio”, en Revista Enfoques Ciencia Política y administración pública, vol. VIII, Nº 12, pp. 27-51. Santiago.

Solera, C. \& Valdivieso, G. (2008), “El éxito escolar de alumnos en condiciones adversas”, en Revista Latinoamericana de Estudios Educativos, vol. XXXVIII, ${ }^{\circ}$ 12, pp. 81-106. Disponible en http://redalyc.uaemex.mx/src/ inicio/ArtPdfRed.jsp?iCve=27012437005

Stefoni, C. (2003), “Inmigración y ciudadanía: la formación de comunidades peruanas en Santiago y la emergencia de nuevos ciudadanos”, en $\mathrm{Po}$ lítica $\mathrm{N}^{\circ}$ 43, pp. 319-336.

Stefoni, C.; Acosta, E.; Gaymer, M.; Casas-Cordero, F. (2008), Niños y niñas inmigrantes en Santiago de Chile. Entre la integración y la exclusión. OIM, Universidad Alberto Hurtado, Santiago.

Subercaseaux, B. (2007), “Raza y nación. El caso de Chile”, en revista $A$ Contra Corriente, Vol. 5, No 1, pp. 29-63, Santiago.

UNICEF, Varios autores (s/d), Estudios sobre estándares jurídicos básicos aplicables a niños y niñas migrantes en situación migratoria irregular en América Latina y el Caribe, Universidad Nacional de Lanús, Centro de Derechos Humanos, Lanús.

Recibido: 25.11.2012

Aceptado: 15.07.2013 